\title{
Hyperimmune colostrum alleviates rheumatoid arthritis in a collagen-induced arthritis murine model
}

\author{
Lan-Hsin Hung, ${ }^{*}$ Chi-Heng Wu, $†$ Bi-Fong Lin, $\dagger^{1}$ and Lucy Sun Hwang ${ }^{* 1}$ \\ *Graduate Institute of Food Science and Technology, College of Bio-Resources and Agriculture, and \\ †Department of Biochemical Science and Technology, College of Life Science, National Taiwan University, Taipei 10617, Taiwan
}

\begin{abstract}
Our aging population and the accompanying decline in immune function is a growing concern that may be addressed by finding natural methods to enhance the immunocompetence of our elderly. Bovine milk and colostrum from cows that have been immunized have been shown to provide additional immunoglobulins and other bioactive molecules that enhance immune function. The purpose of this study was to investigate the ability of hyperimmune bovine colostrum to alleviate the symptoms of rheumatoid arthritis in a murine model. The collagen-induced arthritis DBA/1J murine model was used for this study. Mice were fed colostrum from immunized cows at either 5 or $10 \mathrm{mg} / \mathrm{mouse}$ per day or controls for $49 \mathrm{~d}$. The data showed that the colostrum-fed groups had significantly lower total swelling scores and significantly lower collagen-specific antibody $\left(\operatorname{IgG}_{2 \mathrm{a}}\right)$, inflammation-associated antibody (total $\operatorname{IgG}$ ), and the inflammatory cytokines tumor necrosis factor $\alpha$, IL-2, IL-6, and IFN- $\gamma$. The results strongly suggest that colostrum from immunized cows may have anti-inflammatory activity in a mouse model of rheumatoid arthritis.
\end{abstract}

Key words: rheumatoid arthritis, DBA/1J, collageninduced arthritis, Stolle colostrum

\section{INTRODUCTION}

A report by the US National Institute of Aging indicates that the number of US citizens over age $65 \mathrm{yr}$ is projected to exceed the number of those $4 \mathrm{yr}$ of age and younger between 2015 and 2020 (Haub, 2011). The same aging trend is also occurring throughout much of the developed world and is expected to lead to an increased prevalence of age-related degenerative diseases worldwide (Wong et al., 2014).

\footnotetext{
Received July 26, 2017.

Accepted December 28, 2017

${ }^{1}$ Corresponding authors: bifong@ntu.edu.tw and lshwang@ntu.edu.
} tw
It is expected that this growing population of elderly suffering from degenerative diseases will place significant burdens on virtually all health care systems. Rheumatoid arthritis (RA) is one such degenerative disease with an estimated prevalence of 1 to $2 \%$ in the general population, with higher prevalence with advancing age (Ruffing et al., 2017). Rheumatoid arthritis is an autoimmune disease that causes the destruction of bone and cartilage, persistent synovitis (Feldmann et al., 1996; Firestein, 2003), and chronic disability and may result in severe chronic inflammation along with systemic symptoms (Das and Padhan, 2017; Mańczak and Gasik, 2017).

The etiologic factors involved in RA development are complex and include infections by certain pathogens (Terato et al., 1995; Podolin et al., 2008) and disruptions in helper $\mathrm{T}$ cell ratios (Ma et al., 2005). The pathogenesis of RA can be triggered by pathogens via activation of $\mathrm{T}$ cell subsets, leading to higher IL-2 and IFN- $\gamma$ production and the induction of macrophages (Ma et al., 2009) to secrete proinflammatory cytokines such as tumor necrosis factor (TNF)- $\alpha$, IL-6, and IL12. Activated $\mathrm{T}$ cells also stimulate macrophages and fibrocytes to secrete matrix metalloproteinases that degrade components of the extracellular matrix, resulting in destruction of joint tissue leading to synovitis (Ma and Pope, 2005; McInnes and Schett, 2007). Previous studies showed that modulating the secretion of proinflammatory cytokines such as TNF- $\alpha$ and IFN- $\gamma$ (Manoury-Schwartz et al., 1997) can reduce inflammation in collagen-induced arthritis (CIA) animal models (Feldmann et al., 1996; Manoury-Schwartz et al., 1997; Vermeire et al., 1997).

Many foods have been studied as possible dietary therapies for autoimmune disease (Herbert and Kastan, 1994; Park et al., 2008; Hong et al., 2009). Milk and colostrum are such foods and are often important sources of high-quality nutrition for both young and elderly individuals. Milk and colostrum have been demonstrated to contain many bioactive molecules, including immunoglobulins, lactoferrin, growth factors, and various bioactive peptides (Stelwagen et al., 2009). 
Enhancing and altering the composition of milk may greatly improve the health status of the elderly (Kim et al., 2016). Colostrum is a form of milk produced by the cow just before and after the birth of the calf. Colostrum contains higher levels of nutrients, immune cells, innate immune factors, and immunoglobulins such as IgA, IgG, and IgM compared with milk (Stelwagen et al., 2009). Potential clinical applications of functional milk and colostrum have been suggested because certain functional milks have been shown to exert anti-inflammatory activity (Bello and Allen, 2008, 2009; Chen et al., 2014; Lordan and Zabetakis, 2017). Hyperimmune milk and colostrum, which are produced by hyperimmunizing dairy cows with a polyvalent bacterial vaccine followed by low-temperature processing, contain higher levels of total and antigen-specific immunoglobulins (Gingerich and McPhillips, 2004) compared with their conventional dairy counterparts. Hyperimmune milk has been shown to suppress inflammation in animal models (Owens and Nickerson, 1989; Ormrod and Miller, 1992, 1993; Walter et al., 2011) and hyperimmune milk protein concentrate to alleviate the symptoms of osteoarthritis in human subjects (Colker et al., 2002; Zenk et al., 2002).

Several animal models are available in which an RAlike state can be induced and used to study the etiology and pathogenetic mechanisms involved (Bendele, 2001; Wagner et al., 2008). The CIA mouse model is a well-accepted animal model in which an RA-like state is induced in mice using injections of type-II collagen (CII) in oil emulsion-based adjuvants. Approximately 3 to 4 wk are required to induce RA-like symptoms in the mice (Di Paola and Salvatore, 2008; Edward et al., 2010). The rate of successful RA-like symptom induction varies between different mouse strains, with approximately $80 \%$ success for $\mathrm{DBA} / 1$ mice and 0 to $60 \%$ success for C57BL/6 mice (Brand et al., 2007). For this study, the CIA model was selected because of its similarities to human RA, and male DBA/1 mice were selected because that strain is highly susceptible to the induction of arthritis symptoms by CII injections (Nordling et al., 1992; Bendele, 2001). In the present study, the antiarthritis activity of colostrum from hyperimmunized cows was demonstrated using the CIA DBA/1J mouse model.

\section{MATERIALS AND METHODS}

\section{Hyperimmune Colostrum}

Colostrum from hyperimmunized cows was provided by Stolle International Co. Ltd. (Taipei, Taiwan). Hyperimmune colostrum was produced by hyperimmunizing dairy cows with a polyvalent vaccine consisting of
26 strains of heat-killed bacteria, including Streptococcus pyogenes, Salmonella enteritidis, Escherichia coli, and Salmonella typhimurium. Raw colostrum was collected from the first 3 milkings following calving and was skimmed, pasteurized, and processed to colostrum powder by spray-drying. All processing was performed by Synlait Milk Limited (Ashburton, New Zealand) under contract for Stolle Milk Biologics, Inc. (Cincinnati, $\mathrm{OH}$ ) using a commercial process for producing standard low-heat colostrum to avoid damaging colostral bioactives such as immunoglobulins and lactoferrin (Kobayashi et al., 1991). The colostrum produced contained $66.9 \mathrm{mg} / \mathrm{g}$ of total $\mathrm{IgG}$ (protein $\mathrm{G}$ affinity HPLC) and 171,364 titer units/g of specific IgG ( Salmonella enteritidis-specific IgG ELISA). Powdered colostrum from hyperimmunized cows was suspended in deionized water at a temperature of $45^{\circ} \mathrm{C}$ immediately before gavaging the mice.

\section{Experimental Animals}

The animal study was approved by the Institutional Animal Care and Use Committee of National Taiwan University (IACUC NTU 99-EL-67). All animal care and handling conformed to the National Institute of Health's Guide for the Care and Use of Laboratory Animals. Male DBA/1J mice of approximately $6 \mathrm{wk}$ of age were purchased from the National Laboratory Animal Center (Taipei, Taiwan) and maintained in a temperature-controlled room at $23 \pm 2^{\circ} \mathrm{C}$ on a regulated 12-h light-dark cycle. Mice were housed individually in stainless steel cages with glass water bottles. Mice were held for adaptation for $14 \mathrm{~d}$ before CIA induction. Following the adaptation period, the mice were randomly divided into 5 groups and treated daily as follows: (1) PBS group, no CIA induction, gavaged with $100 \mu \mathrm{L}$ of deionized water as the arthritis-negative control; (2) control group, with CIA induction, gavaged with 100 $\mu \mathrm{L}$ of deionized water as the arthritis-positive control; (3) indomethacin (IDN; Sigma-Aldrich, St. Louis, MO) group, with CIA induction, gavaged with $100 \mu \mathrm{L}$ of IDN as the drug-positive control (the IDN solution contained $0.01 \mathrm{mg}$ of IDN in $100 \mu \mathrm{L}$ of $15 \%$ gelatin from cold-water fish skin; Sigma-Aldrich; Pelus and Strausser, 1976; Taketa et al., 2008); (4) colostrum-M (medium-dose colostrum) group, with CIA induction, gavaged with $5 \mathrm{mg}$ of colostrum (dissolved in $100 \mu \mathrm{L}$ of deionized water); and (5) colostrum-H (high-dose colostrum) group, with CIA induction, gavaged with $10 \mathrm{mg}$ of colostrum (dissolved in $100 \mu \mathrm{L}$ of deionized water). Conversion of animal doses to human-equivalent doses based on body surface area was equivalent to 1.42 and $2.85 \mathrm{~g} / \mathrm{d}$ for medium- and high-dose colostrum, respectively, for a 70-kg human according to guidelines (US 
Food and Drug Administration, 2005). All mice were fed AIN-76 mouse diet prepared in-house according to American Institute of Nutrition standards (American Institute of Nutrition, 1977) and had free access to food and water throughout the study. The swelling scores of mice were determined at 2- to 3 -d intervals. The mice were killed by $\mathrm{CO}_{2}$ asphyxiation after the 49 -d treatment period.

\section{Induction of RA Using Bovine CII Emulsions}

The materials used to conduct the CIA experiment include bovine CII $(2 \mathrm{mg} / \mathrm{mL}$ in $0.05 M$ acetic acid, immunization grade; Chondrex Inc., Redmond, WA); Freund's complete adjuvant (CFA; with $4 \mathrm{mg} / \mathrm{mL}$ of heat-killed Mycobacterium tuberculosis; Chondrex Inc.), and Freund's incomplete adjuvant (IFA; Chondrex Inc.). All reagents were placed on ice during emulsification to avoid denaturing the CII. The CFA/CII emulsion was prepared by first vortexing the CFA before use to ensure that the M. tuberculosis was evenly suspended (Kai et al., 2006). The emulsion was prepared with the CII solution emulsified in CFA (at final ratio of 1:1) using a homogenizer (Series PRO-200 homogenizer; Bertec Enterprise Co. Ltd., Taipei, Taiwan). The CFA was homogenized at medium speed while the CII was added dropwise to the CFA. After all the CII was added, the homogenizer speed was increased to maximum for $1.5 \mathrm{~min}$ to thoroughly emulsify. The appearance and viscosity were visually determined to be that of dense whipped cream, ensuring complete emulsion (Brand et al., 2007). Lack of dispersion upon introducing a drop of emulsion on the surface of water indicated a stable emulsion. The IFA/CII emulsions were prepared the same as the CFA/CII emulsions except IFA was used in place of CFA.

On d 0, DBA/1 mice were anesthetized (pentobarbital, $25 \mathrm{mg} / \mathrm{kg}$, Sigma-Aldrich) before immunization. The tails were sanitized with $70 \%$ ethanol, then wiped dry using sterile gauze. To induce CIA, primary immunizations consisting of $50 \mu \mathrm{L}$ of CFA/CII emulsion were slowly injected intradermally into the base of the tail (Bonnotte et al., 2003) using a microinjector (Hamilton, Reno, NV) and a 26.5-ga syringe needle (BD, Franklin Lakes, NJ). Booster immunizations were implemented at d 21 with $50 \mu \mathrm{L}$ of IFA/CII emulsion injected intradermally into the base of the tail. For the PBS group, PBS was used in place of CII for the emulsion preparations that were used for both the primary immunizations and boosters.

The swelling scores of the paws were recorded every 2 to $3 \mathrm{~d}$, and the concentrations of CII-specific serum $\operatorname{IgG}_{2 \mathrm{a}}$ were analyzed every $14 \mathrm{~d}$. Total serum IgG and cytokines secreted from immune cells were analyzed after $49 \mathrm{~d}$.

\section{Swelling Score}

The severity of paw swelling was evaluated by a qualitative scoring system (Brand et al., 2007). Severity scores for each paw ranged from 0 to 4 , and total swelling scores, ranging from 0 to 16 , were the sum of all 4 paw scores. Scoring of paws was as follows: $0=$ no evidence of redness or swelling; $1=$ slight redness and mild swelling confined to 1 joint or 1 toe; $2=2$ or more toes were swollen or exhibited mild erythema and swelling extending into the paw; $3=$ moderate redness and swelling extending over the entire paw; $4=$ a red, extremely swollen and misshaped paw. Swelling scores were recorded every 2 to 3 d over the 49 -d study period.

\section{Serum Sample Analysis}

Prior to blood sampling, mice were anesthetized with ether. A total of $100 \mu \mathrm{L}$ of blood was sampled from the orbital sinus using microcapillary tubes (Drummond microcaps, Drummond Scientific Co., Broomall, PA). After blood samples were incubated at $4^{\circ} \mathrm{C}$ for 2 $\mathrm{h}$, serum was separated by centrifugation, followed by storage at $-80^{\circ} \mathrm{C}$ until analysis.

Assay of CII-specific serum $\operatorname{IgG}_{2 \mathrm{a}}$ was conducted by ELISA as follows: 96-well plates were coated with $0.5 \mu \mathrm{g} / \mathrm{mL}$ of CII (ELISA grade; Chondrex Inc., Redmond, WA) in collagen dilution buffer (Chondrex Inc.) and incubated overnight at $4^{\circ} \mathrm{C}$. Plates were washed and blocked for $2 \mathrm{~h}$ with blocking buffer (PBS buffer containing 1\% BSA; Sigma-Aldrich) for $2 \mathrm{~h}$ and then washed. A total of $100 \mu \mathrm{L}$ of serum diluted to 1:60,000 with blocking buffer was then added to the wells. After incubation for $2 \mathrm{~h}$ at $4^{\circ} \mathrm{C}$, the wells were washed and $100 \mu \mathrm{L}$ of biotin-conjugated anti-mouse $\mathrm{IgG}_{2 \mathrm{a}}$ (BD Pharmingen, Franklin Lakes, NJ) diluted to 1:3,000 with blocking buffer was added to each well and incubated for $2 \mathrm{~h}$ at $4^{\circ} \mathrm{C}$. Plates were washed and 100 $\mu \mathrm{L}$ of avidin-horseradish peroxidase conjugate (eBioscience, Thermo Fisher Scientific, Waltham, MA) diluted 1:250 in blocking buffer was added to the plates and incubated in the dark for $30 \mathrm{~min}$, then washed, and then incubated with $100 \mu \mathrm{L}$ of tetramethylbenzidine (Clinical Science Products, Mansfield, MA) until optimal color developed. Color development was stopped using $100 \mu \mathrm{L}$ of $2 \mathrm{~N} \mathrm{H}_{2} \mathrm{SO}_{4}$. Absorbance at $450 / 570 \mathrm{~nm}$ was measured using a microtiter plate reader (SpectraMax, Kelowna International Scientific Inc., San Jose, CA). The assay of total serum IgG was performed by ELISA (eBioscience) according to the manufacturer's instructions. 


\section{Assay of Cytokine Production from Immune Cells}

Mice were killed after the 49-d treatment period, and splenocytes (SPN) and peritoneal exudate cells (PEC) were collected (Wu et al., 2017). Single cell suspensions of SPN were prepared from the spleens from each of the mice. Red blood cells were removed by using ammonium-chloride-potassium lysing buffer (formulated with $8.29 \mathrm{~g}$ of $\mathrm{NH}_{4} \mathrm{Cl}, 37.2 \mathrm{mg}$ of $\mathrm{Na}_{2}$ EDTA, and $1.0 \mathrm{~g}$ of $\mathrm{KHCO}_{3}$; distilled water added to a final volume of 1,000 $\mathrm{mL}$ followed by filtration through a $0.22-\mu \mathrm{m}$ filter). The SPN were washed twice with Hanks' balanced salt solution (Sigma-Aldrich) and suspended in RPMI cell culture medium (containing 10\% fetal bovine serum; Gibco, Waltham, MA) at a concentration of $5 \times 10^{6}$ cells/mL per well into 24-well cell culture plates (Corning Inc., Corning, NY). To determine the effects on cytokine secretion, SPN from each mouse were divided into 3 groups and the SPN were stimulated with either nothing (unstimulated) or the mitogen concanavalin A (ConA $; 2 \mu \mathrm{g} / \mathrm{mL}$, Sigma-Aldrich) or CII $(40 \mu \mathrm{g} / \mathrm{mL})$. The SPN cultures were then incubated at $37^{\circ} \mathrm{C}$ in $5 \%$ $\mathrm{CO}_{2}$ for $24 \mathrm{~h}$. After incubation, cell supernatants were collected and stored at $-80^{\circ} \mathrm{C}$ until cytokine analysis. The PEC were seeded at $1.5 \times 10^{6}$ cells $/ \mathrm{mL}$ per well in 24-well plates and treated with or without $10 \mu \mathrm{g} / \mathrm{mL}$ of LPS (Sigma-Aldrich) and then incubated at $37^{\circ} \mathrm{C}$ in $5 \% \mathrm{CO}_{2}$ for $48 \mathrm{~h}$, after which the supernatants were collected and stored at $-80^{\circ} \mathrm{C}$ until cytokine analysis. The analysis of cytokine levels in culture supernatants, including TNF- $\alpha$ (Cho et al., 2008), IL-6 (Manickan et al., 2006), IFN- $\gamma$ (Lin and Wu-Hsieh, 2004), and IL-2 (Ho et al., 2010), was performed by ELISA.

\section{Statistical Analysis}

Data were analyzed by Student's $t$-test and expressed as mean \pm standard error of the mean. Compared with the control group, a 2 -tailed $P$-value of $<0.05$ was considered statistically significant.

\section{RESULTS AND DISCUSSION}

\section{Changes in BW}

The initial BW of mice before immunization ( $8 \mathrm{wk}$ old) and weights before sacrifice (15 wk old) are listed in Table 1. The PBS group (no CII immunizations) had higher BW than the 4 other groups immunized with CII, suggesting that CII immunization and the associated inflammation might cause stress that inhibits weight gain. No significant BW differences were observed between the 4 groups immunized with CII
Table 1. Body weights ${ }^{1}$ of mice from different treatment groups at 8 and 15 wk of age

\begin{tabular}{lccc}
\hline & & \multicolumn{2}{c}{ Mouse BW $(\mathrm{g})$} \\
\cline { 3 - 4 } Treatment $^{2}$ & $\mathrm{n}$ & $8 \mathrm{wk}$ & $15 \mathrm{wk}$ \\
\hline PBS & 10 & $19.6 \pm 0.6$ & $22.5 \pm 0.5^{*}$ \\
Control & 10 & $20.2 \pm 0.5$ & $20.7 \pm 0.3$ \\
Indomethacin & 10 & $19.5 \pm 0.7$ & $20.6 \pm 0.5$ \\
Colostrum-M & 12 & $20.1 \pm 0.5$ & $20.7 \pm 0.6$ \\
Colostrum-H & 10 & $20.2 \pm 0.5$ & $20.6 \pm 0.6$ \\
\hline
\end{tabular}

${ }^{1}$ Values are mean \pm SEM.

${ }^{2} \mathrm{PBS}=$ no collagen-induced arthritis (CIA) induction, gavaged with $100 \mu \mathrm{L}$ of deionized water as the arthritis-negative control. Control $=$ CIA induction, gavaged with $100 \mu \mathrm{L}$ of deionized water as the arthritis-positive control. Indomethacin $=$ CIA induction, gavaged with 100 $\mu \mathrm{L}$ of indomethacin as the drug-positive control. The indomethacin solution contained $0.01 \mathrm{mg}$ of indomethacin in $100 \mu \mathrm{L}$ of $15 \%$ gelatin. Colostrum-M = medium-dose colostrum group with CIA induction, gavaged with $5 \mathrm{mg}$ of colostrum (dissolved in $100 \mu \mathrm{L}$ of deionized water). Colostrum-H = high-dose colostrum group with CIA induction, gavaged with $10 \mathrm{mg}$ of colostrum (dissolved in $100 \mu \mathrm{L}$ of deionized water).

${ }^{*} P<0.05$ compared with control group.

regardless of treatment, suggesting that BW was not a factor in the differences between swelling scores and other measurements for the CII immunized groups.

\section{Swelling Scores}

Our paw swelling score data clearly showed that the CII immunizations were effective at inducing an RAlike state in $100 \%$ of the mice. The changes in swelling scores over time are shown in Figure 1. Swelling and inflammation are clearly observable in all CII-immunized groups but not in any of the PBS groups. Swelling was first observed on the paws approximately $10 \mathrm{~d}$ after the primary immunizations. As expected, the total swelling scores of the PBS group remained at zero throughout the study. The control group began to exhibit increases in swelling scores $(P<0.01)$ compared with the PBS group at d 16 following the primary immunizations. The IDN group began to exhibit significantly lower $(P=0.017)$ swelling scores compared with the control group at $\mathrm{d} 29$ after the primary immunization ( $8 \mathrm{~d}$ after boost), with even greater differences by $\mathrm{d} 35$. The 2 groups that were gavaged with hyperimmune colostrum began to exhibit lower swelling scores compared with the control group by d 24 for colostrum-H $(P=0.026)$ and $\mathrm{d} 29$ for colostrum-M $(P=0.023)$ groups. The colostrum-M and colostrum-H groups both exhibited significantly lower total swelling scores $(P<0.05)$ compared with the control group from d 29 to 49 . At the end of the 49-d study, the average total swelling score of the control group was 10.2 , the IDN group was 6.4 $(P<0.01)$, the colostrum-M group was $6.8(P<0.01)$, and the colostrum-H group was $7.1(P<0.05)$. All 
sample treatment groups showed lower degrees of swelling than the control group. Our data clearly showed that administration of hyperimmune colostrum significantly reduced the swelling scores of mice with CIA with an effectiveness similar to IDN. The colostrum-H group showed consistently lower swelling scores than the colostrum-M group throughout the first $39 \mathrm{~d}$ of the study, suggesting a dose-response effect. However, the differences in swelling scores between the 2 colostrum groups were not observed after d 41, suggesting that both doses were as effective as IDN treatment.

\section{Width and Thickness of Mouse Paws}

The width and thickness of each paw was determined using a caliper after the mice were killed. The average width and thickness of paws are shown in Figure 2. The average width of hind paws of mice from the PBS, IDN, colostrum-M, and colostrum- $\mathrm{H}$ groups were significantly lower than that of mice from the control groups (Figure 2A), whereas widths of forepaws followed the same trend (Figure 2B). Average thickness of hind paws of mice from the PBS, IDN, colostrum-M, and colostrum-H groups was significantly lower than that of mice from the control group (Figure 2C), whereas thickness of forelimbs was also significantly different from that of the control group for mice from the PBS, IDN, colostrum-M, and colostrum-H groups (Figure $2 \mathrm{D})$. We speculate that the reduction of swelling score, thickness, and width of paws of the colostrum-treated groups may be due to the previously described antiinflammatory factors in hyperimmune milk (Owens and Nickerson, 1989; Ormrod and Miller, 1992, 1993). It has been shown that one mechanism by which these hyperimmune anti-inflammatory factors may act is by reducing epithelial cell tight junction permeability, which may inhibit the extravasation of inflammatory white blood cells through tight junctions (Stelwagen and Ormrod, 1998).

\section{IDN and Colostrum Groups Have Lower Serum Ig $G_{2 a}$ Levels}

The CII-specific serum antibodies of the $\operatorname{IgG}_{2 \mathrm{a}}$ isotype have been shown to be strongly associated with the arthritis-like inflammation induced by immunization with CII (Bornstein and Sage, 1980; Courtenay et al., 1980; Cho et al., 2007). Our data showed that serum $\mathrm{IgG}_{2 \mathrm{a}}$ levels of all CII-immunized groups were increased significantly compared with the PBS group 14, 28, and $49 \mathrm{~d}$ following the primary immunizations (Figure 3 ). Serum $\operatorname{IgG}_{2 \mathrm{a}}$ levels were significantly elevated among all CII-immunized groups compared with the PBS group at 14 and $28 \mathrm{~d}$ following the primary immunization, whereas there were no significant differences between the control, IDN, and colostrum groups at these time points. However, by d 49, the serum $\operatorname{IgG}_{2 \mathrm{a}}$ levels for the control group were significantly higher than those for the IDN group and both colostrum groups, suggesting that the IDN group and both colostrum groups exhib-

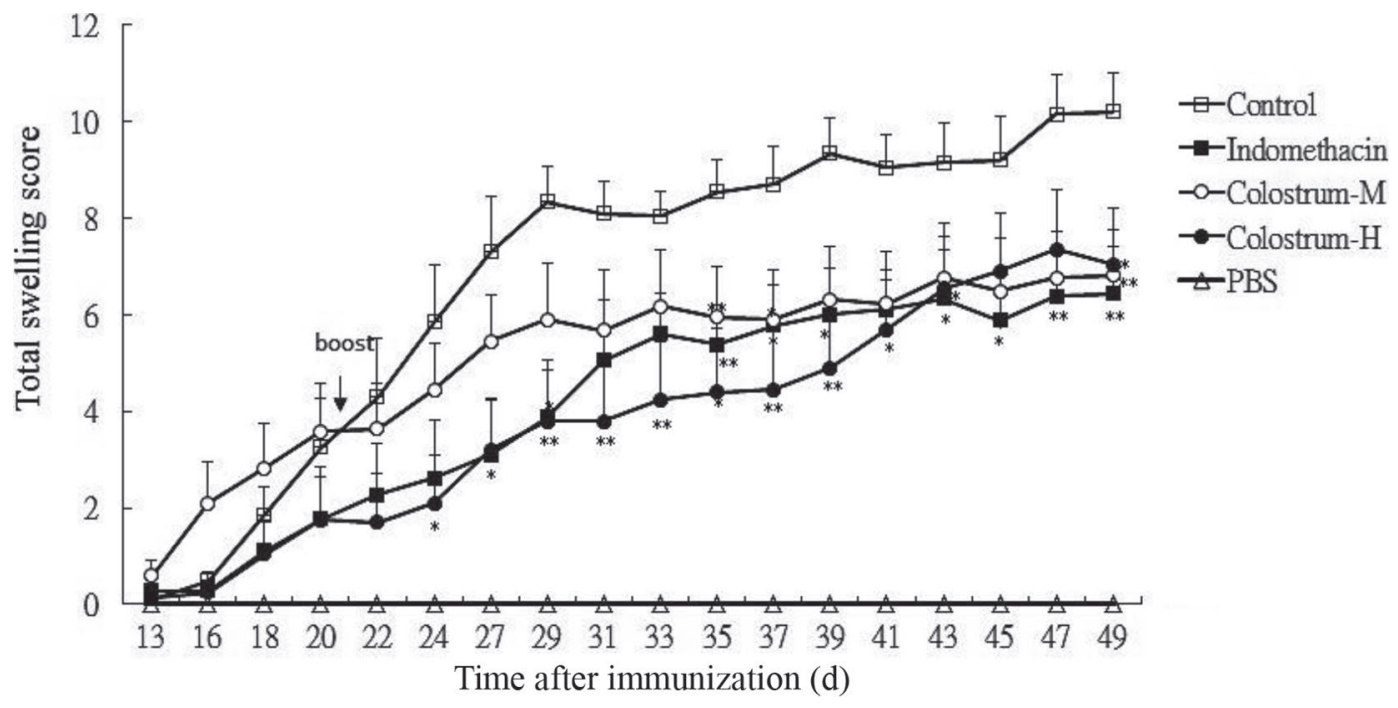

Figure 1. The changes of total swelling score of the 5 groups of mice after $49 \mathrm{~d}$ of treatment. The total swelling score was determined single blinded 3 times per week. Values are mean \pm SEM. ${ }^{*} P<0.05,{ }^{*} P<0.01$ compared with control group. PBS $=$ no collagen-induced arthritis (CIA) induction, gavaged with $100 \mu \mathrm{L}$ of deionized water as the arthritis-negative control. Control = CIA induction, gavaged with $100 \mu \mathrm{L}$ of deionized water as the arthritis-positive control. Indomethacin $=$ CIA induction, gavaged with $100 \mu \mathrm{L}$ of indomethacin as the drug-positive control. The indomethacin solution contained $0.01 \mathrm{mg}$ of indomethacin in $100 \mu \mathrm{L}$ of $15 \%$ gelatin. Colostrum-M $=$ medium-dose colostrum group with CIA induction, gavaged with $5 \mathrm{mg}$ of colostrum (dissolved in $100 \mu \mathrm{L}$ of deionized water). Colostrum-H $=$ high-dose colostrum group with CIA induction, gavaged with $10 \mathrm{mg}$ of colostrum (dissolved in $100 \mu \mathrm{L}$ of deionized water). 
ited anti-inflammatory effects after $49 \mathrm{~d}$ of treatment. Because serum $\operatorname{IgG}_{2 \mathrm{a}}$ is a well-recognized marker for inflammation in the murine CIA model (Brand et al., 2007), our results demonstrate that a 49-d treatment period in this model is suitable to observe the antiinflammatory effects of both IDN and hyperimmune colostrum in this model. We have also shown in this model that treatment of mice with IDN or hyperimmune colostrum has little or no observable anti-inflammatory effects during the acute phase of CIA but does show significant anti-inflammatory effects during the mid to late phases of CIA development.

\section{IDN and Colostrum Groups Have Lower Total Serum IgG Levels}

Our measurements of total serum IgG showed that the IDN, colostrum-M, and colostrum-H groups had lower concentrations after the 49-d treatment period (Figure 4). Because IgG induces proinflammatory re-
(A)

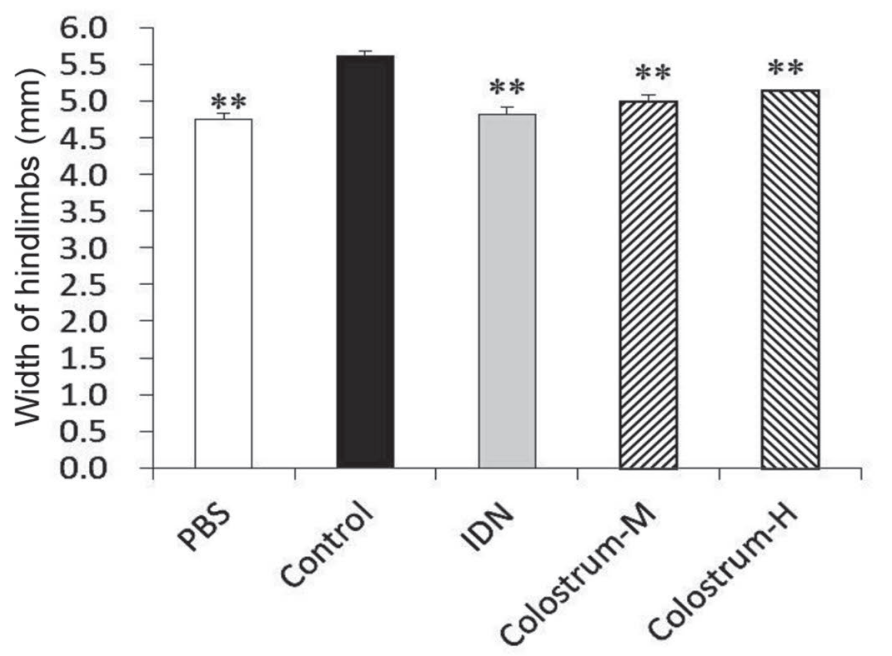

(C)

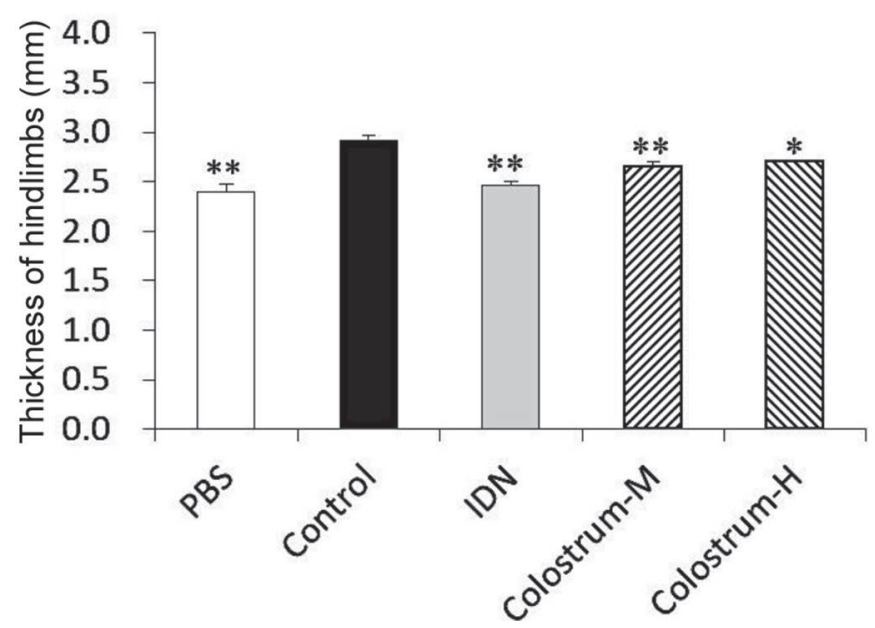

(B)

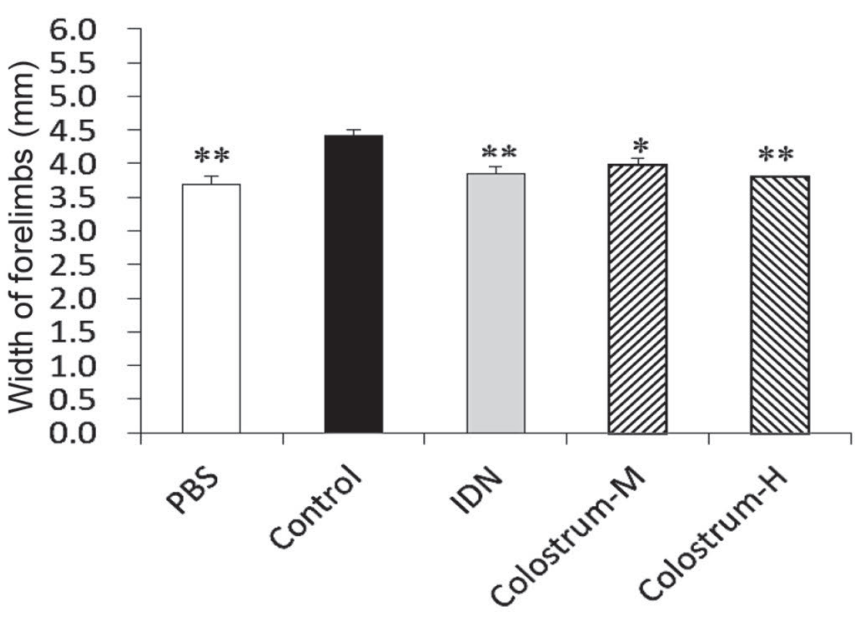

(D)

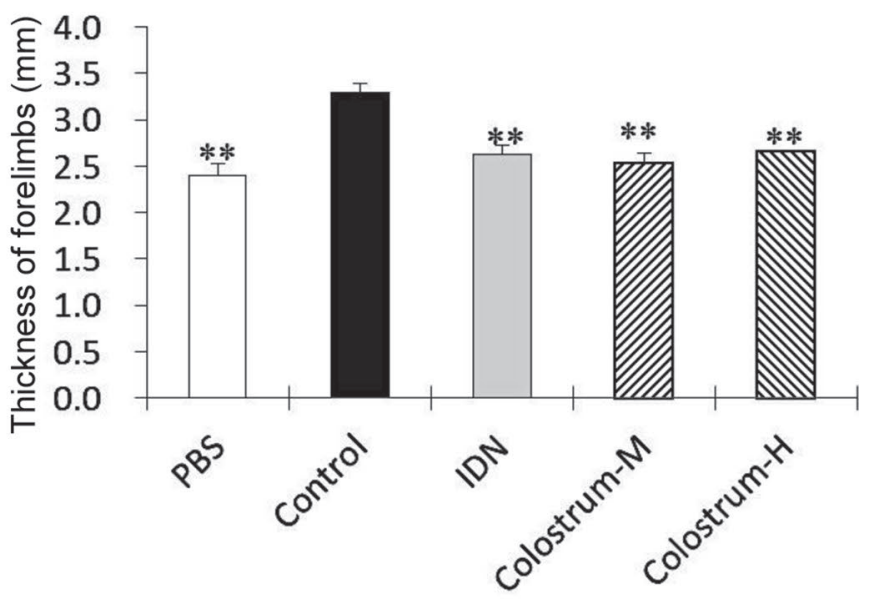

Figure 2. (A) Average width of hindlimbs, (B) average width of forelimbs, (C) average thickness of hindlimbs, and (D) average thickness of forelimbs of DBA/1J mice after $49 \mathrm{~d}$ of treatment. The data were collected by measurement with a caliper to determine the swelling status objectively. Values are mean \pm SEM. ${ }^{*} P<0.05,{ }^{*} P<0.01$ compared with control group. $\mathrm{PBS}=$ no collagen-induced arthritis (CIA) induction, gavaged with $100 \mu \mathrm{L}$ of deionized water as the arthritis-negative control. Control $=$ CIA induction, gavaged with $100 \mu \mathrm{L}$ of deionized water as the arthritis-positive control. IDN = CIA induction, gavaged with $100 \mu \mathrm{L}$ of indomethacin as the drug-positive control. The indomethacin solution contained $0.01 \mathrm{mg}$ of indomethacin in $100 \mu \mathrm{L}$ of $15 \%$ gelatin. Colostrum-M = medium-dose colostrum group with CIA induction, gavaged with $5 \mathrm{mg}$ of colostrum (dissolved in $100 \mu \mathrm{L}$ of deionized water). Colostrum- $\mathrm{H}=$ high-dose colostrum group with CIA induction, gavaged with $10 \mathrm{mg}$ of colostrum (dissolved in $100 \mu \mathrm{L}$ of deionized water). 


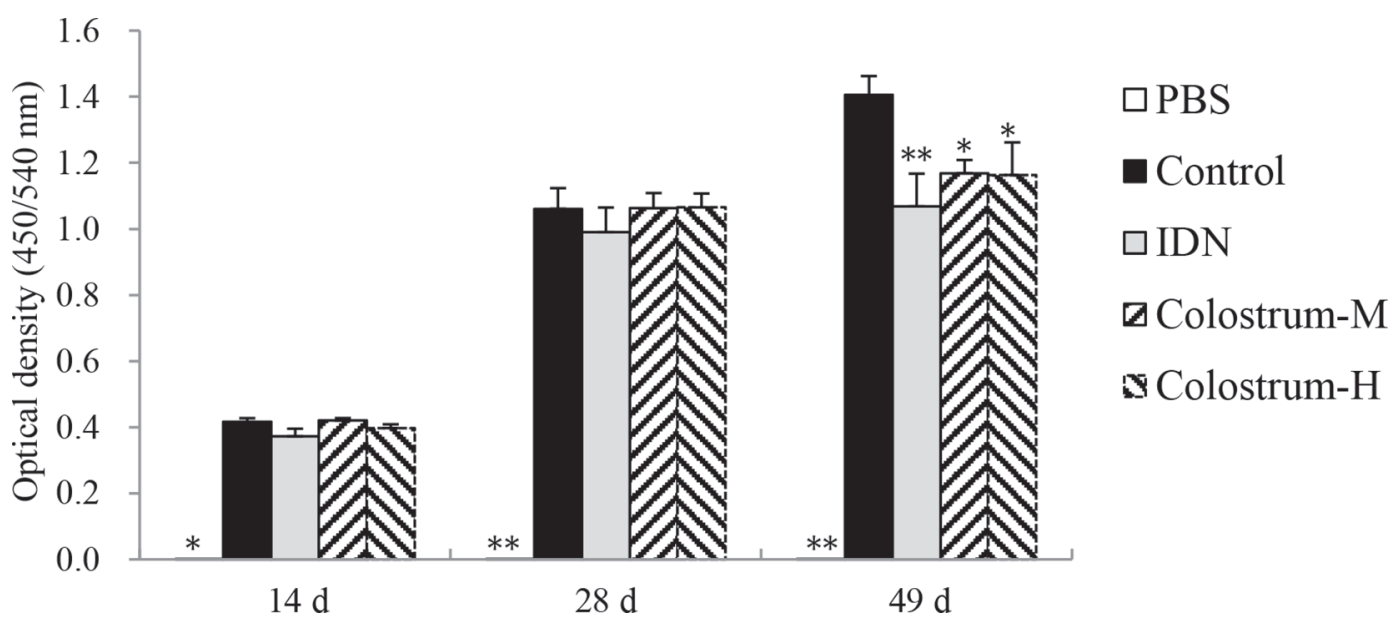

Figure 3. Changes in type II collagen (CII)-specific serum $\operatorname{IgG}_{2 \mathrm{a}}$ levels at 14,28 , and $49 \mathrm{~d}$ of treatment. The blood samples were collected to measure the change in serum CII-specific IgG $\mathrm{Ig}_{2 \mathrm{a}}$ of each treatment group. Assay of CII-specific serum IgG $\mathrm{2a}_{2 \mathrm{a}}$ was conducted by ELISA. Values are mean \pm SEM. ${ }^{*} P<0.05,{ }^{* *} P<0.01$ compared with control group. PBS = no collagen-induced arthritis (CIA) induction, gavaged with $100 \mu \mathrm{L}$ of deionized water as the arthritis-negative control. Control $=$ CIA induction, gavaged with $100 \mu \mathrm{L}$ of deionized water as the arthritis-positive control. IDN = CIA induction, gavaged with $100 \mu \mathrm{L}$ of indomethacin as the drug-positive control. The indomethacin solution contained 0.01 mg of indomethacin in $100 \mu \mathrm{L}$ of $15 \%$ gelatin. Colostrum-M = medium-dose colostrum group with CIA induction, gavaged with 5 mg of colostrum (dissolved in $100 \mu \mathrm{L}$ of deionized water). Colostrum-H = high-dose colostrum group with CIA induction, gavaged with $10 \mathrm{mg}$ of colostrum (dissolved in $100 \mu \mathrm{L}$ of deionized water).

sponses and recruits innate immune effector cells during infection or autoimmune disease (Aschermann et al., 2010; Lo et al., 2013), we again interpret these results to indicate that the IDN and colostrum treatments reduced the level of inflammation in the CIA mouse model.

\section{Proinflammatory Cytokine Levels Are Reduced in IDN and Colostrum Groups}

Rheumatoid arthritis is an autoimmune disease in which the immune system mistakenly attacks normal joint tissues, leading to inflammation and pain (Trentham et al., 1977; Akaogi et al., 2006; Cho et al., 2007). Higher than normal concentrations of inflammatory cytokines such as TNF- $\alpha$, IFN- $\gamma$, IL-6, and IL-2 have been found in rheumatoid synovial tissue (Brennan et al., 1989; Mauri et al., 1996). In our study, cytokine levels of PEC and SPN supernatants were measured after the 49-d treatment period (Tables 2 and 3). Our results show that the concentration of $\mathrm{TNF}-\alpha$ levels (Table 2) from unstimulated PEC cultures was significantly lower for the IDN, colostrum-H, and PBS groups compared with the control group. There were no significant differences in TNF- $\alpha$ levels between groups from the LPS-stimulated PEC cultures. The IL-6 levels in unstimulated PEC cultures were lower for the PBS, IDN, colostrum-M, and colostrum-H groups compared with the control group, but the differences were significant only for the PBS group. The LPS-stimulated PEC culture IL-6 levels were lower for the PBS, IDN,
colostrum-M, and colostrum-H groups compared with the control group, but the differences were significant only for the PBS and colostrum-M groups.

The levels of IL-2 (Table 3) from unstimulated SPN cultures and ConA-stimulated SPN cultures from the control group were significantly higher than those from

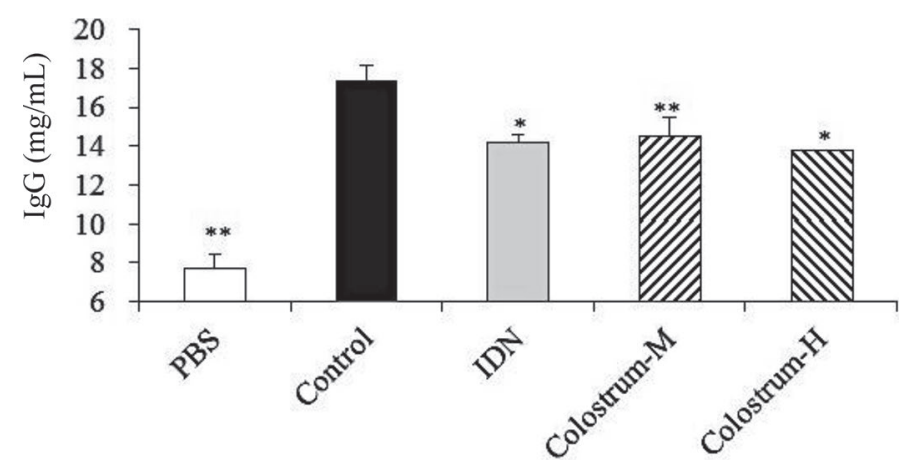

Figure 4. Serum total IgG levels after $49 \mathrm{~d}$ of treatment. The IgG levels of the 5 groups were analyzed to reflect the inflammation status of the individual groups. Values are mean \pm SEM. ${ }^{*} P<0.05$, ${ }^{* *} P<0.01$ compared with control group. $\mathrm{PBS}=$ no collagen-induced arthritis (CIA) induction, gavaged with $100 \mu \mathrm{L}$ of deionized water as the arthritis-negative control. Control = CIA induction, gavaged with $100 \mu \mathrm{L}$ of deionized water as the arthritis-positive control. IDN $=$ CIA induction, gavaged with $100 \mu \mathrm{L}$ of indomethacin as the drug-positive control. The indomethacin solution contained $0.01 \mathrm{mg}$ of indomethacin in $100 \mu \mathrm{L}$ of $15 \%$ gelatin. Colostrum-M = medium-dose colostrum group with CIA induction, gavaged with $5 \mathrm{mg}$ of colostrum (dissolved in $100 \mu \mathrm{L}$ of deionized water). Colostrum- $\mathrm{H}=$ high-dose colostrum group with CIA induction, gavaged with $10 \mathrm{mg}$ of colostrum (dissolved in $100 \mu \mathrm{L}$ of deionized water). 
Table 2. Concentrations ${ }^{1}$ of tumor necrosis factor (TNF)- $\alpha$ and IL-6 in peritoneal exudate cell culture supernatants from DBA/1J mice after $49 \mathrm{~d}$ of treatment

\begin{tabular}{|c|c|c|c|c|c|}
\hline \multirow[b]{2}{*}{ Treatment $^{2}$} & \multirow[b]{2}{*}{$\mathrm{n}$} & \multicolumn{2}{|c|}{ TNF- $\alpha(\mathrm{pg} / \mathrm{mL})$} & \multicolumn{2}{|c|}{ IL-6 (pg/mL) } \\
\hline & & Unstimulated & $\begin{array}{c}\text { LPS } \\
\text { stimulated }\end{array}$ & Unstimulated & $\begin{array}{c}\text { LPS } \\
\text { stimulated }\end{array}$ \\
\hline PBS & 7 & $70.4 \pm 15.8^{*}$ & $182 \pm 45.6$ & $323 \pm 81.8^{*}$ & $104 \pm 248.6^{*}$ \\
\hline Control & 7 & $118.0 \pm 13.7$ & $245 \pm 23.1$ & $631 \pm 46.4$ & $1,708 \pm 130.8$ \\
\hline Indomethacin & 7 & $71.5 \pm 15.1^{*}$ & $191 \pm 20.6$ & $422 \pm 90.2$ & $1,197 \pm 212.5$ \\
\hline Colostrum-M & 8 & $81.8 \pm 12.4$ & $239 \pm 18.6$ & $440 \pm 77.8$ & $1,183 \pm 168.3^{*}$ \\
\hline Colostrum-H & 8 & $71.2 \pm 11.7^{*}$ & $208 \pm 30.8$ & $438 \pm 85.2$ & $1,292 \pm 258.8$ \\
\hline \multicolumn{6}{|c|}{${ }^{1}$ Values are mean \pm SEM. } \\
\hline \multicolumn{6}{|c|}{$\begin{array}{l}{ }^{2} \mathrm{PBS}=\text { no collagen-induced arthritis }(\mathrm{CIA}) \text { induction, gavaged with } 100 \mu \mathrm{L} \text { of deionized water as the arthritis- } \\
\text { negative control. Control = CIA induction, gavaged with } 100 \mu \mathrm{L} \text { of deionized water as the arthritis-positive } \\
\text { control. Indomethacin = CIA induction, gavaged with } 100 \mu \mathrm{L} \text { of indomethacin as the drug-positive control. } \\
\text { The indomethacin solution contained } 0.01 \mathrm{mg} \text { of indomethacin in } 100 \mu \mathrm{L} \text { of } 15 \% \text { gelatin. Colostrum-M }= \\
\text { medium-dose colostrum group with CIA induction, gavaged with } 5 \mathrm{mg} \text { of colostrum (dissolved in } 100 \mu \mathrm{L} \text { of } \\
\text { deionized water). Colostrum-H = high-dose colostrum group with CIA induction, gavaged with } 10 \mathrm{mg} \text { of co- } \\
\text { lostrum (dissolved in } 100 \mu \mathrm{L} \text { of deionized water). } \\
* P<0.05 \text { compared with control group. }\end{array}$} \\
\hline
\end{tabular}

the other 4 groups. However, the levels of IL-2 from CII-stimulated SPN were significantly lower only in the PBS and colostrum groups compared with the control. The proinflammatory cytokine IFN- $\gamma$ also plays an important role in CIA development in the animal model (Manoury-Schwartz et al., 1997; Vermeire et al., 1997). Our data showed that IFN- $\gamma$ levels were significantly lower in the unstimulated, ConA-stimulated, and CIIstimulated SPN supernatants from the colostrum-M, colostrum-H, and PBS groups. The IFN- $\gamma$ levels were significantly lower in only the ConA-stimulated and CII-stimulated SPN supernatants from the IDN group.

Although not always significant, generally lower levels of inflammatory cytokines TNF- $\alpha$ and IL-6 seen with the colostrum- $\mathrm{M}$ and colostrum- $\mathrm{H}$ treatment groups suggest a moderate anti-inflammatory effect on macrophages similar to that of IDN. However, IL-2 and IFN- $\gamma$ levels in all SPN cultures of the colostrum-
$\mathrm{M}$ and colostrum- $\mathrm{H}$ treatment groups are always significantly lower than the control group. Because IL-2 and IFN- $\gamma$ play important roles in the regulation of growth and differentiation of T-cells, this suggests that hyperimmune colostrum may directly or indirectly affect T-cell activation induced by CII immunizations. Both colostrum-M and colostrum-H groups showed strong anti-inflammation activity similar to IDN without statistically significant differences, indicating that the maximum dose was most likely reached with the colostrum-M group dosage. However, the levels of IFN- $\gamma$ secreted by SPN in the colostrum-H group were half of those in the colostrum-M group, suggesting a dose effect on IFN- $\gamma$ secretion by SPN. Further studies will be required to fully understand the mechanisms by which hyperimmune colostrum modulates TNF- $\alpha$, IL-6, IL-2, and IFN- $\gamma$ production and T-cell function in the CIA mouse model.

Table 3. Concentrations ${ }^{1}$ of IL-2 and IFN- $\gamma$ in splenocyte culture supernatants from DBA/1J mice after $49 \mathrm{~d}$ of treatment

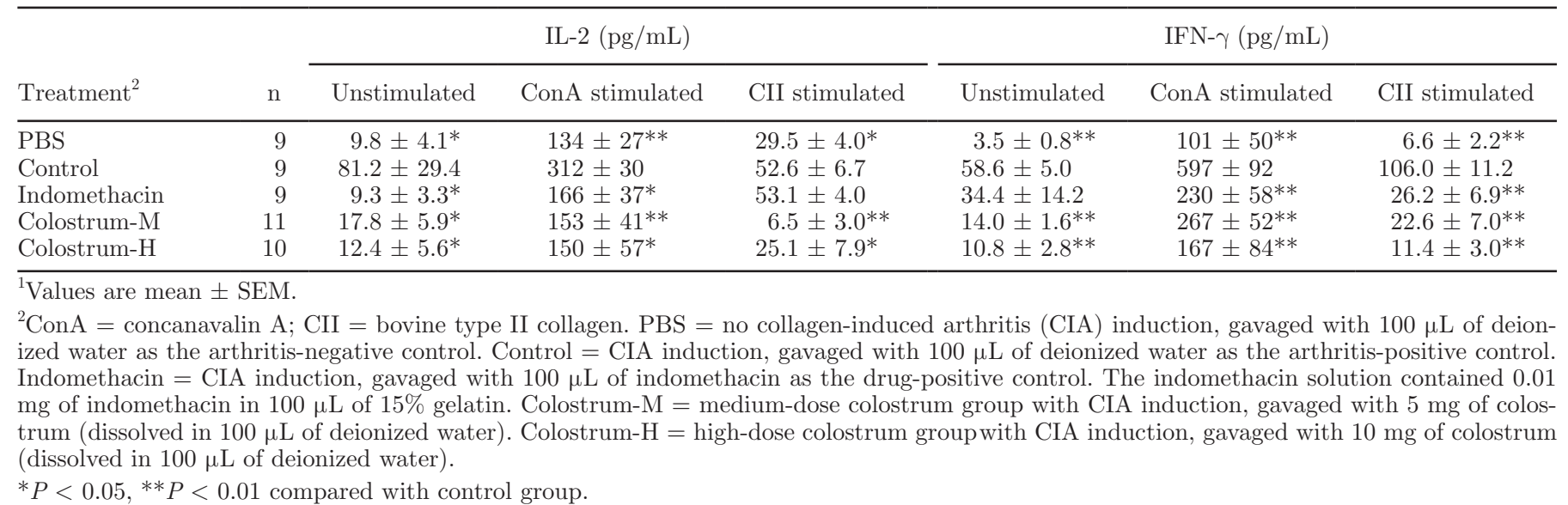


In an earlier preliminary study, CIA was first induced over $49 \mathrm{~d}$. After the induction of arthritis at d 49, the mice were randomly separated into treatment groups. The same treatments as in the current study were then administered for an additional $56 \mathrm{~d}$. After the 56-d treatment period, there were no significant differences in anti-inflammatory effects due to the different treatments (L. H. Hung, unpublished data). These results suggest that the colostrum and IDN treatments are far more effective when administered to mice during the early induction phase of CIA versus administration following the full development of advanced arthritis.

\section{CONCLUSIONS}

The CIA mouse model was used in this study because it is a widely used model of autoimmune arthritis that possesses many similarities to human RA. In this study, it was found that the administration of hyperimmune colostrum during the early stages of CIA development results in a modulating effect on inflammatory markers and on the progression of symptoms of arthritis in mice. These results suggest that hyperimmune colostrum has the potential to alleviate the symptoms of RA in mice. Additional research would be needed to determine whether hyperimmune colostrum could alleviate the inflammatory symptoms of RA in humans.

\section{ACKNOWLEDGMENTS}

The financial support from the Ministry of Health and Welfare of the Republic of China (no. DOH098TD-F-113-098014) and the colostrum provided by Lanfar International Co. Ltd. (Taipei, Taiwan) are deeply appreciated. We are grateful to Hsueh-Yun Lu, Ruby Yang, and all colleagues and students at National Taiwan University who helped in conducting this study, and we thank Bob Stohrer (Stohrer LLC, Cincinnati, $\mathrm{OH})$ for help editing the manuscript. We declare no conflicts of interest.

\section{REFERENCES}

Akaogi, J., T. Barker, Y. Kuroda, D. C. Nacionales, Y. Yamasaki, B. R. Stevens, W. H. Reeves, and M. Satoh. 2006. Role of non-protein amino acid L-canavanine in autoimmunity. Autoimmun. Rev. 5:429-435. https://doi.org/10.1016/j.autrev.2005.12.004.

American Institute of Nutrition. 1977. Report of the American Institute of Nutrition ad hoc Committee on Standards for Nutritional Studies. J. Nutr. 107:1340-1348.

Aschermann, S., A. Lux, A. Baerenwaldt, M. Biburger, and F. Nimmerjahn. 2010. The other side of immunoglobulin G: Suppressor of inflammation. Clin. Exp. Immunol. 160:161-167. https://doi.org/ 10.1111/j.1365-2249.2009.04081.x.

Bello, T. R., and T. M. Allen. 2008. An intensive approach in treatment of clinical equine protozoal myeloencephalitis. J. Equine Vet. Sci. 28:479-483. https://doi.org/10.1016/j.jevs.2008.07.004.
Bello, T. R., and T. M. Allen. 2009. Clinical experience using microlactin for the treatment of equine inflammatory disease. J. Equine Vet. Sci. 29:547-550. https://doi.org/10.1016/j.jevs.2009.05.004.

Bendele, A. 2001. Animal models of rheumatoid arthritis. J. Musculoskelet. Neuronal Interact. 1:377-385.

Bonnotte, B., M. Gough, V. Phan, A. Ahmed, H. Chong, F. Martin, and R. G. Vile. 2003. Intradermal injection, as opposed to subcutaneous injection, enhances immunogenicity and suppresses tumorigenicity of tumor cells. Cancer Res. 63:2145-2149.

Bornstein, P., and H. Sage. 1980. Structurally distinct collagen types. Annu. Rev. Biochem. 49:957-1003. https://doi.org/10.1146/ annurev.bi.49.070180.004521.

Brand, D. D., K. A. Latham, and E. F. Rosloniec. 2007. Collageninduced arthritis. Nat. Protoc. 2:1269-1275. https://doi.org/10 .1038/nprot.2007.173.

Brennan, F. M., D. Chantry, A. Jackson, R. Maini, and M. Feldmann. 1989. Inhibitory effect of TNF alpha antibodies on synovial cell interleukin-1 production in rheumatoid arthritis. Lancet 2:244-247.

Chen, H. Y., O. Mollstedt, M. H. Tsai, and R. B. Kreider. 2014. Potential clinical applications of multi-functional milk proteins and peptides in cancer management. Curr. Med. Chem. $21: 2424-2437$

Cho, Y. G., M. L. Cho, S. Y. Min, and H. Y. Kim. 2007. Type II collagen autoimmunity in a mouse model of human rheumatoid arthritis. Autoimmun. Rev. 7:65-70. https://doi.org/10.1016/j .autrev.2007.08.001.

Cho, H. J., M. R. Seon, Y. M. Lee, J. Kim, J. K. Kim, S. G. Kim, and J. H. Park. 2008. 3,3'-Diindolylmethane suppresses the inflammatory response to lipopolysaccharide in murine macrophages. J. Nutr. 138:17-23.

Colker, C. M., M. Swain, L. Lynch, and D. A. Gingerich. 2002. Effects of a milk-based bioactive micronutrient beverage on pain symptoms and activity of adults with osteoarthritis: A doubleblind, placebo-controlled clinical evaluation. Nutrition 18:388-392. https://doi.org/10.1016/S0899-9007(01)00800-0.

Courtenay, J. S., M. J. Dallman, A. D. Dayan, A. Martin, and B. Mosedale. 1980. Immunisation against heterologous type II collagen induces arthritis in mice. Nature 283:666-668. https://doi .org/10.1191/0961203304lu1094oa.

Das, S., and P. Padhan. 2017. An overview of the extraarticular involvement in rheumatoid arthritis and its management. J. Pharmacol. Pharmacother. 8:81-86. https://doi.org/10.4103/jpp.JPP _194_16.

Di Paola, R., and C. Salvatore. 2008. Predictivity and sensitivity of animal models of arthritis. Autoimmun. Rev. 8:73-75.

Feldmann, M., F. M. Brennan, and R. N. Maini. 1996. Rheumatoid arthritis. Cell 85:307-310.

Firestein, G. S. 2003. Evolving concepts of rheumatoid arthritis. Nature 423:356-361. https://doi.org/10.1038/nature01661.

Gingerich, D. A., and C. A. McPhillips. 2005. Analytical approach to determination of safety of milk ingredients from hyperimmunized cows. Regul. Toxicol. Pharmacol. 41:102-112. http://dx.doi.org/ https://doi.org/10.1016/j.yrtph.2004.10.002.

Haub, C. 2011. World Population Aging: Clocks Illustrate Growth in Population Under Age 5 and Over Age 65. Population Reference Bureau, Washington, DC.

Herbert, V., and T. S. Kastan. 1994. Alfalfa, vitamin E, and autoimmune disorders. Am. J. Clin. Nutr. 60:639-640.

Ho, P., X. Wei, and G. T. Seah. 2010. Regulatory T cells induced by Mycobacterium chelonae sensitization influence murine responses to bacille Calmette-Guerin. J. Leukoc. Biol. 88:1073-1080. https://doi.org/10.1189/jlb.0809582.

Hong, Y. H., C. J. Huang, S. C. Wang, and B. F. Lin. 2009. The ethyl acetate extract of Alfalfa sprouts ameliorates autoimmune-prone disease of MRL-lpr/lpr mice. Lupus 18:206-215. https://doi.org/ $10.1177 / 0961203308095450$

Hurley, W. L., and P. K. Theil. 2011. Perspectives on immunoglobulins in colostrum and milk. Nutrients 3:442-474. https://doi.org/ $10.3390 /$ nu3040442.

Kai, H., K. Shibuya, Y. Wang, H. Kameta, T. Kameyama, S. TaharaHanaoka, A. Miyamoto, S. Honda, I. Matsumoto, A. Koyama, T. 
Sumida, and A. Shibuya. 2006. Critical role of M. tuberculosis for dendritic cell maturation to induce collagen-induced arthritis in $\mathrm{H}-2 \mathrm{~b}$ background of C57BL/6 mice. Immunology 118:233-239. https://doi.org/10.1111/j.1365-2567.2006.02361.x.

Kim, M. J., U. S. Jung, S. W. Jeon, J. S. Lee, W. S. Kim, S. B. Lee, Y. C. Kim, B. Y. Kim, T. Wang, and H. G. Lee. 2016. Improvement of milk fatty acid composition for production of functional milk by dietary phytoncide oil extracted from discarded pine nut cones in Holstein dairy cows. Asian-australas. J. Anim. Sci. 29:1734-1741.

Kobayashi, T., T. Ohmori, M. Yanai, G. Kawanishi, Y. Yoshikai, and K. Nomoto. 1991. Protective effect of orally administering immune milk on endogenous infection in X-irradiated mice. Agric. Biol. Chem. 55:2265-2272.

Lin, J. S., and B. A. Wu-Hsieh. 2004. Functional T cells in primary immune response to histoplasmosis. Int. Immunol. 16:1663-1673.

Lo, M. S., D. Zurakowski, M. B. Son, and R. P. Sundel. 2013. Hypergammaglobulinemia in the pediatric population as a marker for underlying autoimmune disease: A retrospective cohort study. Pediatr. Rheumatol. Online J. 11:42. https://doi.org/10.1186/1546 -0096-11-42.

Lordan, R., and I. Zabetakis. 2017. Invited review: The anti-inflammatory properties of dairy lipids. J. Dairy Sci. 100:4197-4212.

Ma, Y., and R. M. Pope. 2005. The role of macrophages in rheumatoid arthritis. Curr. Pharm. Des. 11:569-580.

Mańczak, M., and R. Gasik. 2017. Cervical spine instability in the course of rheumatoid arthritis-imaging methods. Reumatologia 55:201-207. https://doi.org/10.5114/reum.2017.69782.

Manickan, E., J. S. Smith, J. Tian, T. L. Eggerman, J. N. Lozier, J. Muller, and A. P. Byrnes. 2006. Rapid Kupffer cell death after intravenous injection of adenovirus vectors. Mol. Ther. 13:108-117.

Manoury-Schwartz, B., G. Chiocchia, N. Bessis, O. Abehsira-Amar, F. Batteux, S. Muller, S. Huang, M. C. Boissier, and C. Fournier. 1997. High susceptibility to collagen-induced arthritis in mice lacking IFN-gamma receptors. J. Immunol. 158:5501-5506.

Mauri, C., R. O. Williams, M. Walmsley, and M. Feldmann. 1996. Relationship between Th1/Th2 cytokine patterns and the arthritogenic response in collagen-induced arthritis. Eur. J. Immunol. 26:1511-1518. https://doi.org/10.1002/eji.1830260716.

McInnes, I. B., and G. Schett. 2007. Cytokines in the pathogenesis of rheumatoid arthritis. Nat. Rev. Immunol. 7:429-442. https://doi .org/10.1038/nri2094.

Nordling, C., S. Kleinau, and L. Klareskog. 1992. Down-regulation of a spontaneous arthritis in male DBA/1 mice after administration of monoclonal anti-idiotypic antibodies to a cross-reactive idiotope on anti-collagen antibodies. Immunology 77:144-146.

Ormrod, D. J., and T. E. Miller. 1992. A low molecular weight component derived from the milk of hyperimmunised cows suppresses inflammation by inhibiting neutrophil emigration. Agents Actions 37:70-79.

Ormrod, D. J., and T. E. Miller. 1993. Milk from hyperimmunized dairy cows as a source of a novel biological response modifier. Agents Actions 38:C146-C149.

Owens, W. E., and S. C. Nickerson. 1989. Evaluation of an anti-inflammatory factor derived from hyperimmunized cows. Exp. Biol. Med. 190:79-86.

Park, J. H., J. M. Lee, S. N. Kim, S. H. Lee, S. H. Jun, J. H. You, K. S. Ahn, and H. Kang. 2008. Treatment with SI000413, a new herbal formula, ameliorates murine collagen-induced arthritis. Biol. Pharm. Bull. 31:1337-1342.

Pelus, L. M., and H. R. Strausser. 1976. Indomethacin enhancement of spleen-cell responsiveness to mitogen stimulation in tumorous mice. Int. J. Cancer 18:653-660.
Podolin, P. L., B. J. Bolognese, D. C. Carpenter, T. G. Davis, R. A. Johanson, J. H. Fox, E. Long 3rd, X. Dong, R. W. Marquis, S. M. Locastro, G. J. Terfloth, E. Kurali, J. J. Peterson, B. R. Smith, M. S. McQueney, D. S. Yamashita, and E. A. Capper-Spudich. 2008. Inhibition of invariant chain processing, antigen-induced proliferative responses, and the development of collagen-induced arthritis and experimental autoimmune encephalomyelitis by a small molecule cysteine protease. J. Immunol. 180:7989-8003.

Rosloniec, E. F., M. Cremer, A. H. Kang, L. K. Myers, and D. D Brand. 2010. Collagen-induced arthritis. Curr. Protoc. Immunol. $89: 15.5 .1-15.5 .25$

Ruffing V., and C. O. Bingham III. 2017. Rheumatoid arthritis signs and symptoms. Accessed June 2017. https://www.hopkinsarthritis .org/arthritis-info/rheumatoid-arthritis/ra-symptoms/.

Stelwagen, K., E. Carpenter, B. Haigh, A. Hodgkinson, and T. T. Wheeler. 2009. Immune components of bovine colostrum and milk. J. Anim. Sci. 87:3-9. https://doi.org/10.2527/jas.2008-1377.

Stelwagen, K., and D. J. Ormrod. 1998. An anti-inflammatory component derived from milk of hyperimmunised cows reduces tight junction permeability in vitro. Inflamm. Res. 47:384-388.

Taketa, T., A. Sakai, S. Tanaka, K. Nakai, K. Menuki, H. Yamane, K. Tanaka, and T. Nakamura. 2008. Selective cyclooxygenase-2 inhibitor prevents reduction of trabecular bone mass in collageninduced arthritic mice in association with suppression of RANKL/ OPG ratio and IL-6 mRNA expression in synovial tissues but not in bone marrow cells. J. Bone Miner. Metab. 26:143-151. https:// doi.org/10.1007/s00774-007-0808-2.

Terato, K., D. S. Harper, M. M. Griffiths, D. L. Hasty, X. J. Ye, M. A. Cremer, and J. M. Seyer. 1995. Collagen-induced arthritis in mice: Synergistic effect of E. coli lipopolysaccharide bypasses epitope specificity in the induction of arthritis with monoclonal antibodies to type II collagen. Autoimmunity 22:137-147.

Trentham, D. E., A. S. Townes, and A. H. Kang. 1977. Autoimmunity to type II collagen an experimental model of arthritis. J. Exp. Med. 146:857-868.

US Food and Drug Administration. 2005. Guidance for industry: Estimating the maximum safe starting dose in initial clinical trials for therapeutics in adult healthy volunteers. Accessed March 2009. https://www.fda.gov/downloads/drugs/guidances/ucm078932 .pdf.

Vermeire, K., H. Heremans, M. Vandeputte, S. Huang, A. Billiau, and P. Matthys. 1997. Accelerated collagen-induced arthritis in IFNgamma receptor-deficient mice. J. Immunol. 158:5507-5513.

Wagner, S., J. Bindler, and E. Andriambeloson. 2008. Animal models of collagen-induced arthritis. Curr. Prot. Pharmacol. 5:5.51.

Wong, W. L., X. Su, X. Li, C. M. Cheung, R. Klein, C. Y. Cheng, and T. Y. Wong. 2014. Global prevalence of age-related macular degeneration and disease burden projection for 2020 and 2040: A systematic review and meta-analysis. Lancet Glob. Health 2:e106e116. https://doi.org/10.1016/S2214-109X(13)70145-1.

Wu, C. H., T. Z. Huang, and B. F. Lin. 2017. Folate deficiency affects dendritic cell function and subsequent $\mathrm{T}$ helper cell differentiation. J. Nutr. Biochem. 41:65-72. https://doi.org/10.1016/j.jnutbio 2016.11.008.

Zenk, J. L., T. R. Helmer, and M. A. Kuskowski. 2002. The effects of milk protein concentrate on the symptoms of osteoarthritis in adults: An exploratory, randomized, double-blind, placebo-controlled trial. Curr. Therapeutic Res. 63:430-442. https://doi.org/ 10.1016/S0011-393X(02)80049-2. 